\title{
Hacia una arqueología dialéctica: una heurística y una explicación del fenómeno Moche
}

\author{
Towards a dialectical archaeology: a heuristics and an explanation of the Moche \\ phenomenon
}

Henry Tantaleán ${ }^{\mathrm{i}}$

RESUMEN

En este artículo se propone una heurística inspirada en la dialéctica para explicar las relaciones históricas entre las diferentes entidades que constituyen el mundo como alternativa a las perspectivas teleológicas utilizadas en arqueología. Dicha heurística se desprende de la información arqueológica, etnohistórica, histórica, antropológica y de la experiencia vital. En esta perspectiva, existe una serie de entidades que están inmersas y entrelazadas en relaciones dialécticas materiales, históricas y contingentes que pueden ser de convivencia, tensión y/o contradicción. Luego de explicar esta serie de elementos y sus relaciones, utilizamos dicha heurística para explicar el fenómeno Moche desarrollado en la Costa Norte del Perú entre los siglo III y VII de nuestra era.

Palabras clave: Heurística,Teleología, Contingencia, Relaciones Dialécticas, Sociedad Moche.

\begin{abstract}
This article proposes a heuristic inspired by dialectics to explain the historical relationships between the various entities that constitute the world, as an alternative to teleological perspectives used in archaeology. This heuristic moves away from archaeological, ethnohistorical, historical, and anthropological information as well as life experience. In this perspective, there exist a number of entities that are immersed and intertwined in dialectical, historically contingent, material relationships that may coexist in tension and/or conflict. After explaining this set of elements and their relationships, we apply use this heuristic to explain the Moche phenomenon that developed on the north coast of Peru between the III and VII centuries AD.
\end{abstract}

Keywords: Heuristics, Teleology, Contingency, Dialectical Relationships, Moche Society.

i Investigador Asociado, Instituto Francés de Estudios Andinos, Lima/Investigador Prometeo, Escuela Superior Politénica del Litoral, Guayaquil. Correo-e: henrytantalean@yahoo.es 
El origen de la domesticación de plantas y animales, la aparición de las ciudades o el surgimiento de los primeros estados son tópicos clásicos en la arqueología en diferentes áreas del mundo $y$, especialmente en el área andina que justamente fue uno de los principales focos de estos desarrollos prístinos. Independientemente de ser precursores, los orígenes de estos fenómenos sociales siempre generan una serie de explicaciones arqueológicas que ven el proceso desde un punto nuclear y que, como centros locales y regionales de innovación e irradiación, generan que otras sociedades tengan como punto de cambio la asimilación de nuevas formas de vida. Sin embargo, muchas veces estas explicaciones arqueológicas no toman en cuenta el presente del momento histórico de la sociedad en la que estos orígenes de alguna innovación se produjeron, resultando casi siempre teleologías, las más populares de ellas, las que se inspiran en el evolucionismo social (Benjamín, 2008 [1939-1940]).

Para comenzar a superar dichas teleologías es importante reconocer que los fenómenos históricos se produjeron de una manera mucho más compleja que la simple articulación de pasos - etapas históricas de una manera progresiva, secuencial y ordenada. Por el contrario, la dinámica mediante la cual se producen los fenómenos sociales es muchas veces contingente $y$ azarosa, aunque siempre condicionada por las condiciones objetivas y materiales que poseen las entidades que componen y las decisiones sociales tomadas por los seres humanos en las situaciones histórica' que les toca vivir. Por ello, creemos que es necesario reconocer las relaciones dialécticas generadas en y entre las entidades que protagonizan el proceso histórico para proporcionar una imagen mucho más completa del mismo.

A un nivel más regional, desde la empíria conocida en la actualidad, es evidente que los paisajes sociales políticos y económicos nunca fueron homogéneos o simétricos. Por el contrario, observamos que las historias particulares de cada comunidad producen necesariamente diferentes paisajes sociales en momentos históricos sincrónicos. Dada la dinámica histórica en las mismas comunidades señalada arriba, el paisaje social se presentará desigual a lo largo del tiempo también debido a una relación dialéctica externa entre las comunidades de seres humanos. De este modo, la situación histórica de cada comunidad contribuye a la formación de dicho paisaje social.

Por tanto, resulta importante reconocer que dichas situaciones históricas de desarrollos desiguales son parte del escenario del paisaje social. Más allá de las particularidades que se observan en la explicación de dichas comunidades, existen y son necesarias relaciones dialécticas dentro y fuera de las comunidades $y$ entre dichas formaciones históricas para que se produzcan cambios interna y externamente. Esta síntesis o cambio histórico producido incluye resultados positivos o negativos para la comunidad entera. Dichos cambios en los paisajes sociales siempre serán dependientes de las condiciones objetivas precedentes, las cuales se encuentran materializadas en el paisaje social.

De este modo, esta perspectiva dialéctica de las sociedades se contrapone a las visiones teleológicas de la historia al integrar I) la naturaleza de las entidades involucradas en la historia, 2) las relaciones dialécticas entre las entidades protagonistas, 3) las prácticas y decisiones sociales (praxis) tomadas para superar o catalizar las situaciones de tensión y contradicción y 4) la contingencia y el azar como parte del cambio histórico.

Así, en este artículo se propone una heurística inspirada en la dialéctica para explicar los fenómenos observados por los arqueólogos en el pasado a través de sus restos materiales. Además, se proponen una serie de entidades que componen el mundo y sus respectivas potencias generan una serie de relaciones dialécticas. Finalmente, se toma como caso de estudio a la sociedad Moche de la costa norte del Perú del I milenio de nuestra era para reconocer como se habrían dado estas relaciones dialécticas en el pasado prehispánico.

\section{HACIA UNA ARQUEOLOGÍA DIALÉCTICA}

La dialéctica a la que nos referiremos en este artículo se puede rastrear en la historia de la filosofía desde los primeros filósofos griegos (Heráclito, Platón y Aristóteles) pero solamente se convierte en un sistema filosófico en Hegel y se transforma en método de estudio de la realidad objetiva y la historia humana con Marx (Abbagnano, 197I [1958]; Bobbio, 197I [1958]; Sandor, I986; Patterson, 2003). 
En diferentes líneas de investigación dentro de las ciencias sociales, la dialéctica ha recobrado un importante interés para explicar la dinámica de cómo se producen y transforman sus objetos de conocimiento: las sociedades. Para ello, en sus investigaciones retoman las relaciones dialécticas que se puede reconocer entre sujetos y objetos, sociedad y naturaleza, entre diferentes sociedades e, incluso, para cuestiones epistemológicas en la relación dialéctica entre teoría y praxis. Así, la dialéctica ha sido utilizada por diferentes investigadores para tratar de comprender la realidad social (por ejemplo, Bourdieu, 1977; Giddens, 1984; Callinicos, 2004; Žižek, 2006).

De la misma manera, en la arqueología realizada en las últimas décadas, la dialéctica ha sido tomada en cuenta a diferentes niveles de manera implícita y explícita por autores que proceden de diferentes matrices teóricas como la materialista histórica (Marquardt, 1992; McGuire, 1992, 1998; McGuire y Saitta, 1996; Saitta y McGuire, 1998; Crumley, 200I; Patterson, 2004, 2005a; Lull, 2007; Bate, 20I2), la procesual (Brumfiel, 1992; Blantonet al. 1996; Pauketat, 2007) y la post-procesual (Tilley 1982; Miller y Tilley, 1984; Shanks y Tilley, 1987; Shanks, 2007; Hodder, 1995).

En términos generales, todos los anteriores autores identifican la existencia de una relación entre elementos opuestos en una dimensión de encuentro y desencuentro, de coexistencia y tensión que, finalmente, devendrá en una superación de ambos estados u elementos en un nuevo estado o síntesis. Estos autores han asumido una perspectiva crítica tanto de la forma en la que se hace la arqueología como también han reconocido, a través de su propia práctica arqueológica al enfrentarse con los objetos arqueológicos, un mundo que se encuentra en tensión y en movimiento constante.

Como investigadores, que también experimentamos y reconocemos que el mundo funciona de esta manera, en este artículo hacemos un ejercicio por reconocer la dialéctica en el campo arqueológico tanto de manera teórica como práctica. Nuestra perspectiva dialéctica está fundamentada en una visión del mundo realista y materialista y basada en la evidencia antropológica, etnohistórica, sociológica, histórica, una teoría de observación de la materialidad arqueológica y, cómo no, la propia experiencia vital. Toda esta evidencia acumulada genera una heurística ${ }^{2}$ para reconocer el funcionamiento del mundo a través de la materialidad social, en este caso, la arqueológica.

Para nosotros, una arqueología que deje de lado la tensión que existe en el mundo $y$, consecuentemente en la sociedad, no tiene la necesidad de reconocer a la dialéctica como parte de la explicación del cambio y como algo consustancial a las sociedades y el mundo. En ese sentido, las arqueologías neo-evolucionistas a pesar de entender que existe dicho cambio y que, incluso, la dialéctica es importante para que este se realice, termina produciendo una perspectiva teleológica en la cual la sociedad humana progresa hacia un fin predeterminado que siempre resulta siendo un presente positivo y mejor que el anterior (Patterson, 1990: 196). La arqueología y la historia nos demuestran que no es así. Situaciones históricas que debían tener un "destino" no lo han realizado de manera tal. Para nosotros, la historia conlleva "aciertos" como también "errores", los cuales se originan y se encuentran en las condiciones previas al resultado histórico dado.

Así, la arqueología encuentra que, en muchos casos, los procesos prehistóricos e históricos se resuelven o devienen en situaciones inesperadas para el investigador. En ese sentido, la dialéctica no es algo que se pueda reconocer desde el Estado final - consecuencia del proceso histórico (teleología) sino que se deberá re-conocer desde el estudio de las situaciones históricas previas al cambio, analizando las relaciones dialécticas que vinculan a cada entidad, especialmente los seres humanos. Como investigadores de fenómenos sociales, la perspectiva dialéctica resulta importante al reconocer dichas convivencias, tensiones, contradicciones $y$, consecuentes superaciones o cambios presentes en la historia humana. En ese mismo sentido, debemos resaltar que las prácticas sociales son muchas veces las fuerzas más importantes existentes en las situaciones dialécticas y su superación son las que generan un cambio importante en la historia humana.

\section{Entidades Componentes en las Situaciones Históricas}

En los últimos años se ha generado una fuerte crítica al "eurocentrismo", "antropocentrismo" 
y "modernidad cartesiana" que incluye el rechazo de términos ontológicos binarios como naturaleza y cultura, sujeto y objeto, etc. en las ciencias sociales (Por ejemplo, Latour, I99। [2007]). Por extensión, lo mismo ha ocurrido en algunas de las arqueologías contemporáneas posmodernas (por ejemplo, Shanks, 2007; Olsen, 2010). Esta separación de las entidades obviamente resulta antropocéntrica y merma la capacidad de reconocimiento de la integración y dinámica de los fenómenos que se dan en la realidad.

Para superar dichas categorías, en la perspectiva aquí presentada se reconocen tres grandes entidades a tomar en cuenta en las relaciones dialécticas que desarrollaremos en las cuales la potencia ${ }^{3}$ existente en diferentes grados en ellas genera las relaciones dialécticas que veremos más adelante: i) Entidades potenciadorasprimarias (agua, aire, tierra (minerales)), ii) Entidades potenciadoras secundarias (plantas, animales y seres humanos), iii) Entidades potenciadas (ecofactos y artefactos) (Figura I).

Las entidades potenciadoras primarias son las entidades prístinas y desde las cuales se generaron las demás entidades. Existe toda una dialéctica interna en estas entidades que se puede llevar hasta el nivel atómico de las entidades potenciadoras primarias pero a ese nivel esta dialéctica pertenece al mundo físico-químico que genera cambios en la materia y que afecta circunstancialmente a la historia humana. Así, las entidades potenciadoras primarias proyectan una fuerza que procede de su misma naturaleza (por ejemplo, un temblor, un tsunami, un aluvión o una inundación). Por ello, puede superar a la fuerza de los seres humanos, lo cual en su peor faceta genera desastres para estos y sus posesiones.

Por otra parte, las entidades potenciadoras secundarias son cualquier organismo que establece una relación vital entre sus pares y que se proyecta también hacia las entidades potenciadoras primarias. Estas entidades ofrecen una resistencia diferente que las entidades potenciadoras primarias puesto que poseen capacidad efectiva de reacción. Sin embargo, es importante señalar que las entidades potenciadoras secundarias al morir perderán la capacidad de resistencia y acción en el mundo que tenían previamente. Así, regresan al mundo de las entidades potenciadoras primarias. Los seres humanos están contenidos en las entidades potenciadoras secundarias. Los seres sociales, son los seres humanos que a través de sus interrelaciones y con otras entidades construyen comunidades. Estos seres sociales, si bien, se gestan y nacen como seres biológicos devienen seres sociales desde el momento de su nacimiento en que comienzan ser socializados y la reproducción de su mundo siempre se realizará de forma colectiva ${ }^{4}$. Así, los seres sociales son los seres humanos interrelacionados desde que comienzan a transformar el mundo por medio de su acción social y colectiva sobre este, lo cual como relación dialéctica produjo su propia humanidad.

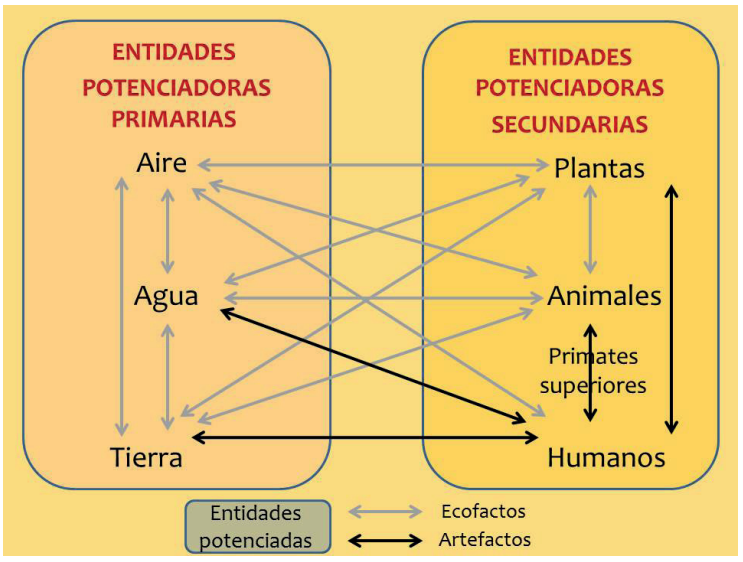

Figura 1: entidades potenciadoras primarias, entidades potenciadoras secundarias y entidades potenciadas. Las flechas en doble sentido representan las relaciones dialécticas externas que se dan entre las entidades y las consecuentes entidades potenciadas que dan lugar.

Figure 1: primary potentiating entities, secondary potentiating entities and potentiated entities. Arrows in double sense depicts external dialectical relationships occurred between entities and potentiated entities resulting

Como consecuencia de las relaciones dialécticas establecidas entre las entidades potenciadoras primarias y secundarias se generan entidades potenciadas: ecofactos y artefactos. Los ecofactos resultan de las relaciones dialécticas entre entidades diferentes a las que se generan conscientemente un producto con un objetivo concreto. En el caso de los artefactos, el ser humano ha incorporado un trabajo $y$, por tanto, se les ha conferido una fuerza que se presentará contenida en el mismo artefacto. Asimismo, esta fuerza contenida es lo que genera la apariencia de que los artefactos poseen "agencia"s (la capacidad de actuar creativamente sobre el mundo material) ni tienen la posibilidad de reproducirse por sí mismos. Tal aparente agencia no procede originalmente 
del mismo artefacto sino de la fuerza previamente incorporada en el momento de su producción social lo cual podemos definir como una "agencia proyectada".

Por lo anterior, la percepción que se pueda tener de los artefactos y sus relaciones dialécticas solamente se encuentra en la subjetividad del observador (por ejemplo, Tilley, 1994, 2004; Jones y Cloke, 2008; Hodder, 2012). En ese mismo sentido, en los últimos años se ha generado todo un debate acerca de su percepción por ciertos grupos humanos, en especial del mundo andino y amazónico. Esto ha supuesto un tratamiento significativo a nivel de percepciones en la cuales ingresa el perspectivismo (Viveiros de Castro, 2010), el animismo (Descola, 2005; Sillar, 2009) y hasta las percepciones humanas del tipo simétrico y relacional con respecto a objetos y animales (Haber, 2009; Swenson y Warner, 2012; Angelo, 20I4). Como señalamos arriba, esta "agencia" resulta discutible desde nuestra perspectiva.

Habiendo proporcionado la definición de las entidades, pasaremos ahora a explicar las relaciones dialécticas entabladas entre estos.

\section{Relaciones dialécticas entre entidades}

Originalmente, lo que genera una primera relación dialéctica es la ubicación en el espacio que "naturalmente" enfrenta a las entidades. Entre estas entidades existen relaciones dialécticas generadas por su potencia, las cuales los enfrentan y conducen a un cambio de estado. La potencia, como dijimos arriba, procede de la energía almacenada en las mismas entidades y que se transfiere a través de la materia y se proyecta hacia fuera de las mismas. Con respecto a la potencia de los seres humanos, esta se desarrolla de formas conscientes o inconscientes generando, muchas veces, relaciones dialécticas tensas y hasta contradictorias con las otras entidades (potenciadoras primarias y transformadas) y entre los mismos seres sociales. Esta última será una relación dialéctica interna entre los miembros de una comunidad de seres sociales. Asimismo, esta potencia desplegada o fuerza social puede ser dirigida conscientemente hacia un objetivo concreto. De este modo, las relaciones dialécticas que consideramos significativas para la historia humana se dan hacia fuera de las comunidades de seres sociales (relaciones dialécticas externas) y entre los mismos seres sociales (relaciones dialécticas internas).

\section{RELACIONES DIALÉCTICAS ENTRE SERES SOCIALES}

Es necesario señalar que todas estas relaciones dialécticas tienen diferentes intensidades en las situaciones históricas que se den y que poseen diferentes gradaciones de intensidad que van desde la convivencia hasta la contradicción. Dentro de esta gradación de relaciones dialécticas podemos identificar las siguientes: i) Convivencia, ii) Tensión y, iii) Contradicción.

La convivencia es una relación entre entidades que se reconocen, se necesitan, se complementan y coexisten manteniendo un estado relativamente estable aunque con mínimos grados de tensión. La tensión establece una evidente relación de desajuste y rechazo de las entidades relacionadas y que predispone a la relación a un cambio, aunque este siempre puede ser catalizado y/o liberado por los seres humanos o la aparición de otros objetos. Finalmente, la contradicción es la exacerbación de la tensión lo que, finalmente, devendrá una superación dialéctica de la situación anterior, lo cual produce un cambio o salto histórico.

Es muy posible que estas relaciones no sean las únicas pero, por el momento, nos permiten muy bien para adelantar nuestra heurística. Asimismo, también se pueden establecer estas relaciones dialécticas de manera simultánea $\mathrm{e}$, incluso, se pueden superponer, sobre todo, la convivencia y la tensión. Sin embargo, lo que aquí queremos resaltar es que existen relaciones dialécticas que son fundamentales o primarias en cada situación histórica y que son las que producen el cambio en dichas relaciones y en el Estado inicial de los participantes. Dicho esto, ahora pasaremos a plantear estas relaciones dialécticas para el mundo andino.

\section{HACIA UNA ARQUEOLOGÍA DIALÉCTICA EN LOS ANDES PREHISPÁNICOS}

En algunos casos protohistóricos (etnohistóricos) y arqueológicos de los Andes prehispánicos se ha podido evidenciar la 
materialización de dualidades que se encuentran inter-relacionadas (Isbell, 1977; Hocquenghem, 1987; Burger, 1994; Moore, 1995; Allen, 1998; Lau, 2004: 177, 2014: 314, Swenson, 2014). Estas dualidades inter-relacionadas nos ofrecen la oportunidad de aproximarnos, por medio de la arqueología, al reconocimiento de relaciones dialécticas. Así, la materialización de dichas dualidades se podría explicar como un intento de las sociedades prehispánicas por reproducir las relaciones dialécticas entre diferentes entidades en diversas intensidades. De hecho, algunas representaciones prehispánicas parecen estar señalando la existencia de tales percepciones en la prehistoria andina, como por ejemplo, el "tema de la revuelta de los objetos” Moche (Quilter, 1990; Swenson, 20I4) (Figura 2) o las narraciones recogidas en el siglo XVI por los extirpadores de idolatrías como las atribuidas a Francisco de Ávila (Arguedas, 2007 [1966]).

Por la universalidad que tienen las prácticas sociales y su historia, las relaciones entre humanos y objetos o entre humanos y humanos no debería causar sorpresa encontrar relaciones dialécticas como parte de la existencia y su idealización por parte de las sociedades del mundo prehispánico. De hecho, dichas relaciones dialécticas se pueden reconocer en ejemplos reconocidos en el mundo incaico tanto a nivel arqueológico como etnohistórico. Así, por ejemplo, desde la información arqueológica disponible más temprana podemos rastrear posibles relaciones dialécticas materializadas desde el período Formativo (I800-500 a.C.) (Burger, 1994) e, incluso, se puede explorar su existencia en algunos ejemplos todavía por investigar más profundamente durante el período Precerámico Tardío o Arcaico Tardío (3000-I800 a.C.) (Shady, 2006). Por supuesto, en este artículo no se puede exponer la infinidad de relaciones dialécticas que se dieron en los casos particulares de la prehistoria andina. Pero, si aporta un caso en el que las relaciones dialécticas pueden explicar resultados históricos producto de su existencia y su dinámica. Así, en lo que queda de este artículo nos centraremos en el caso de los Moche.

\section{El Caso de Los Moche}

La sociedad conocida como Moche o Mochica es una de las mejores estudiadas en la

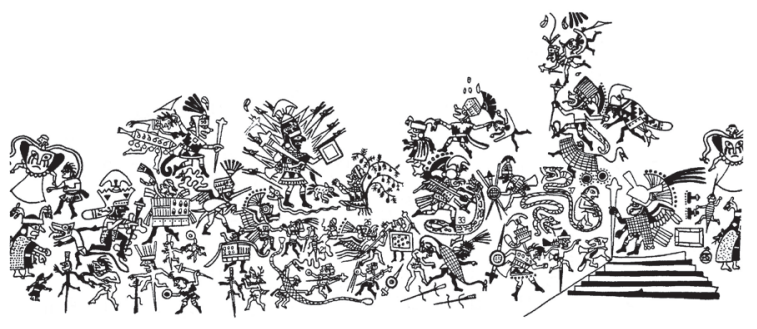

Figura 2: desarrollo del tema de la Revuelta de los Objetos del Vaso de Munich según Kutscher 1983. Tomado de Quilter 1990.

Figure 2: Roll-out of the Revolts of Objects theme from Munich vase after Kutscher 1983 (Quilter 1990).

arqueología andina (por ejemplo, Donnan, 1978; Alva, 1988; Alva y Donnan, 1993; Bawden, 1996; Pillsbury (ed.), 200I; Bourget y Jones (eds.), 2008; Quilter y Castillo,2010; Chapdeleine, 2010a). Importantes proyectos arqueológicos han revelado numerosos contextos arqueológicos que nos ofrecen importantes datos sobre la forma de vida de los seres humanos relacionados con esta sociedad (Castillo, 20I3). Obviamente, existe toda una serie de seres sociales que se encuentran dentro de lo denominado como Moche pero la herencia de la arqueología histórico-cultural ha condicionado su explicación (Makowski, 2008: 56, 2009: 53; Uceda et al.: 2009: 105). Pese a ello, dicha denominación nos permite presentar al lector un fenómeno que esperamos ver con más detalle en esta visión dialéctica de la sociedad vinculada con un territorio concreto y unas prácticas sociales vinculadas con objetos y sitios producidos en un estilo que los arqueólogos reconocen como Moche.

Con respecto a las explicaciones de su naturaleza sociopolítica, en los últimos años se ha dado una tendencia a ver al fenómeno Moche como algo fragmentado (Castillo y Donnan, 1994; Bawden, 1996; Castillo y Quilter, 20 I0; Donnan, 20I I) e, incluso, solamente como una ideología y ya no como una entidad política y económica de tipo estatal (Quilter,20 I0;Tinoco, 2010; Quilter y Koons, 20I2; Swenson, 20I4). Pese a ello, en este artículo, siguiendo a otros investigadores (Castillo y Uceda, 2008: 716; Uceda, 2010a; Chapdeleine, 20I0b; Donnan, 2010), para nosotros el fenómeno Moche denominado específicamente como los Moches del Sur, conformó un Estado de tipo teocrático-militarista el cual se hizo evidente entre los siglos IV y VII de nuestra era (Moche III y IV) (Chapdelaine et al., 200I: 370; Castillo y Uceda, 2008: 716; Millaire, 2009b: I52) (Figura 
3). Obviamente, este fue un espacio de tiempo en el que el Estado Moche atravesó por diferentes y alternantes niveles de integración económica, política e ideológica y ejerció una ocupación discontinúa del territorio. El "área nuclear" de este Estado fueron los valles de Moche y Chicama. Este Estado se habría expandido hacia el sur hacia los valles de Virú, Chao, Santa y Nepeña aunque, como veremos, dadas las variadas relaciones dialécticas, existieron diferentes niveles de relación, asimilación y/o control de estos valles (también ver Shimada, 2010). El centro político-ceremonial y asentamiento principal del Estado Moche fue el complejo de las Huacas del Sol y La Luna ubicado en la margen izquierda el valle bajo de Moche en el actual Departamento de la Libertad, en la Costa Norte del Perú (Figuras 4 y 5). Este Estado prehispánico fue precedido por una larga tradición de comunidades presentes en la costa norte prehispánicas. De este modo, la existencia y pervivencia del estado moche se basó en el legado dejado por estas comunidades precedentes.

\section{El Origen de Los Moche}

A partir del II siglo antes de nuestra era, en los valles bajos y medios de los ríos Chicama, Moche y Virú, se estableció una relación dialéctica de convivencia y tensión entre grupos de seres sociales vinculados con el estilo cerámico Gallinazo (Chapdeleine et al., 200I; Mujica, 2007: 68; Millaire y Morlion, 2009) dentro de un paisaje de desarrollo desigual. Así, por ejemplo, la variedad fina del estilo cerámico Gallinazo (Gallinazo Negativo y Carmelo Negativo) definida originalmente en el valle bajo del Virú (Bennett, 1950), estaría originalmente vinculada a una elite (Uceda et al., 2009: II9) o, incluso, a la existencia de un Estado desde el siglo II a.C. (Fogel 1993; Millaire, 2009a: 12, 2010a) ${ }^{6}$. Este panorama de surgimiento de elites locales habría beneficiado la tensión entre los poblados de estos valles (relación dialéctica de tensión entre seres sociales dominantes o elites) y llevado a la generación de grupos militares y político-religiosos encargados de establecer el control y manejo de las entidades potenciadoras primarias como el agua y la tierra y de la materia prima necesaria para la producción de artefactos.

Así, el surgimiento de lo Moche contaba con un trabajo acumulado por las comunidades precedentes y la producción primaria de alimentos (relación dialéctica entre los seres sociales y otras

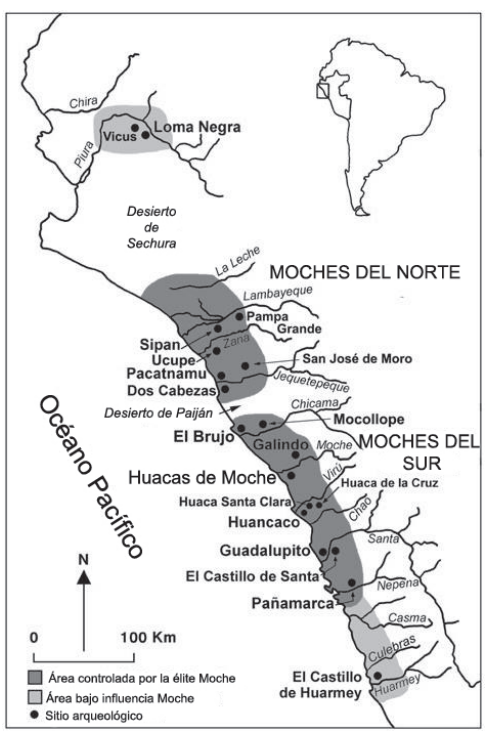

Figura 3: Territorios Moche según Chapdeleine 2010

Figure 3: Moche territories after Chapdeleine 2010

entidades primarias (tierra y agua) y secundarias (plantas y animales)) estaba en pleno desarrollo habiendo dominado, como lo hicieron sus antecesores, la producción agrícola y ganadera (domesticación de plantas y animales). Asimismo, en las diferentes comunidades de estos valles ya existía una producción de artefactos a través del uso de objetos inorgánicos como el barro, la arcilla, los minerales, etc.

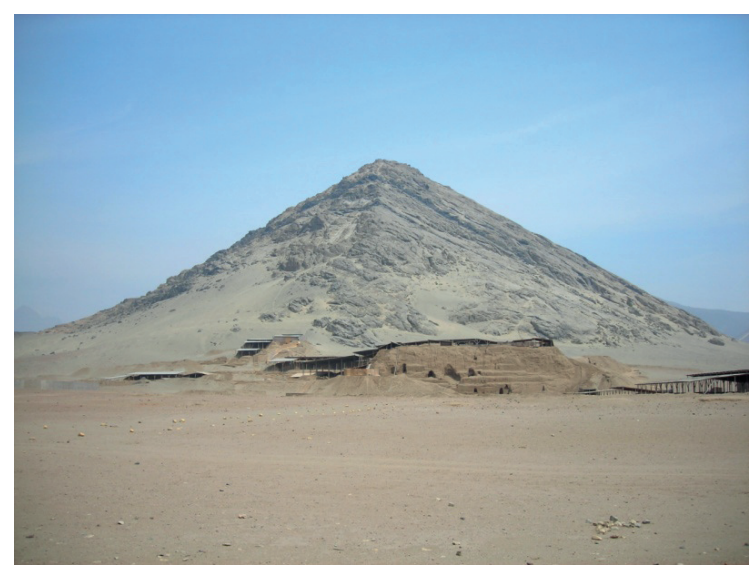

Figura 4: Cerro Blanco y la Huaca de la Luna. Foto tomada por Henry Tantaleán.

Figure 4: Cerro Blanco and Huaca de la Luna. Photograph by Henry Tantaleán. 


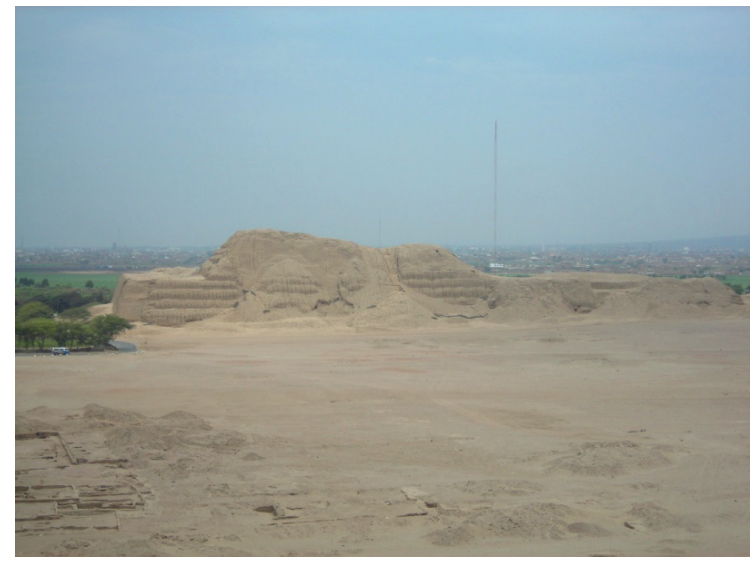

Figura 5: Huaca de El Sol, Valle de Moche

Figure 5: Huaca de El Sol, Moche Valley

Por tanto, la superación de la relación dialéctica de tensión (seres sociales $\leftrightarrow$ otras entidades primarias y secundarias) que da surgimiento a la base social de las comunidades del valle de Moche es la que produce la extensión de la producción de alimentos a nivel de agricultura extensiva (Uceda y Castillo, 2008). Esta superación y cambio histórico produce la ampliación de la concentración de seres sociales (producción de seres sociales) y artefactos en poblados como las primeras ocupaciones de la Huaca del Sol y de la Luna (Topic, 1977: 5I-128, I38; Makowski, 2009: 36; Uceda et al., 2009: II0), un patrón similar a lo que ocurría contemporáneamente en los sitios de Mocollope y El Brujo en el valle de Chicama (Attarian, 2009; Mujica, 2007: 8I; Franco y Gálvez, 2009) (Figura 6). Estas nuevas comunidades pudieron haber solventado la relación de tensión mediante la generación de una forma de vida comunitaria. Sin embargo, sus relaciones de tensión y sus decisiones políticas condujeron a la diferenciación socioeconómica. La primera de ellas fue la que dividió a las comunidades entre seres sociales productores principalmente de artefactos y seres sociales principalmente controladores $y$ consumidores de artefactos.

Así, las primeras concentraciones permanentes de sujetos en torno a la religión ${ }^{7}$ formaron la base para la generación de grupos especializados y alejados de la reproducción de entidades potenciadoras primarias y la producción de artefactos. Este grupo de especialistas a tiempo

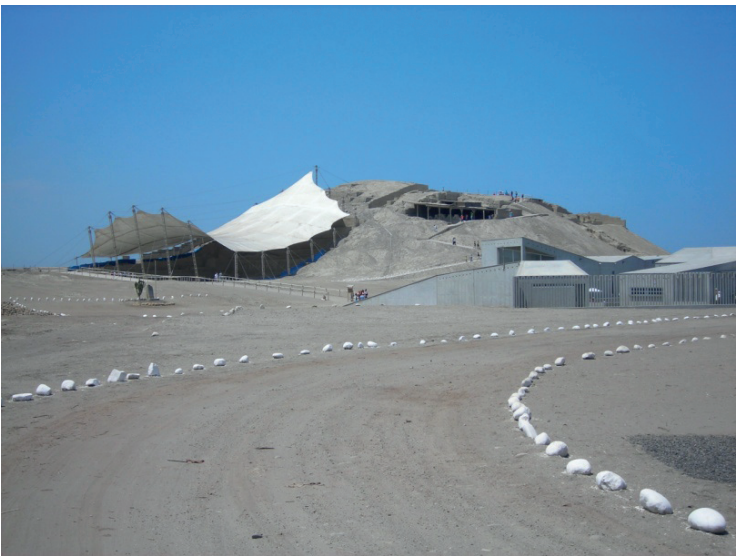

Figura 6: Huaca Cao, Complejo El Brujo, valle de Chicama

Figure 6: Huaca Cao, El Brujo Complex, Chicama valley

completo se diferenció de los grupos productores, los cuales vivían en aldeas y caseríos relacionados con las campos de cultivo y el litoral (Billman, 2002; Castillo y Uceda, 2008: 707). Estas relaciones dialécticas de tensión y contradicción adentro y fuera de las comunidades del valle condujeron a la formación del Estado Moche. Una vez que los seres sociales que controlaba la religión se hicieron con el control de los principales asentamientos, entre ellos Huaca del Sol y la Luna, se contrapusieron a la comunidad productora de alimentos (entidades potenciadoras secundarias: plantas y animales silvestres y domesticados) y artefactos entrando a un nuevo momento de tensión y contradicción. De esta manera, se genera una nueva relación dialéctica de tensión y contradicción entre estos dos grupos de seres sociales: uno que trata de establecer su poder político y económico y el otro de mantener su autonomía económica y política. La superación de esta contradicción se produce finalmente cuando las elites, por medio de la coerción religiosa y física hacia los otros seres sociales, institucionalizan su poder económico y político. La nueva situación que contiene relaciones tensas pero controladas por la elite moche por medio del Estado se extendería entre los siglos II y VII d.C. (Uceda, 20I0a: I57), tiempo en el que se reconoce la existencia del estado Moche, cuyo máximo poder económico y político se albergaba en los principales sitios de los valles de Moche y Chicama. Pero ahora veamos con más detalle cómo se dieron las relaciones dialécticas dentro y fuera del Estado Moche. 
Relaciones Dialécticas en el Estado Moche

Por cuestiones expositivas y corriendo el riesgo de simplificarlas aquí dividimos a las principales relaciones dialécticas ocurridas en el Estado moche en I) relaciones dialécticas entre Seres Sociales y otras entidades primarias y secundarias, 2) relaciones dialécticas entre Seres Sociales y 3) Relaciones Dialécticas entre el Estado Moche y otras formaciones sociales. Como veremos, estas relaciones dialécticas casi siempre se entrelazan y afectan a los mismos seres sociales y otras entidades y producen tensiones de diferentes niveles. Lo que aquí se quiere resaltar, como dijimos anteriormente, es que existen ciertas relaciones dialécticas fundamentales que generarían situaciones y cambios durante el desarrollo histórico de lo conocido como el Estado Moche.

I.- Relaciones dialécticas entre seres sociales y otras entidades primarias y secundarias

Como vimos con anterioridad, los valles de Moche y Chica matenían asentada a toda una base social con desarrollos económicos y políticos importantes (Mujica, 2007; Billman, 2010: I8I; Bourget, 20I0; Millaire, 2010a). Esta fue una base social necesaria, la cual se generó en las comunidades mediante relaciones dialécticas de convivencia y produjo seres sociales (Sutter, 2009: 139). Asimismo, como legado de los seres sociales precedentes y su propia producción se contaba con un conjunto de entidades potenciadoras primarias y secundarias, ecofactos y artefactos.

Así, la relación dialéctica primaria que se establece es la que enfrenta a los seres sociales con otras entidades primarias y secundarias, en un paisaje ya domesticado previamente. Dicha relación es una de convivencia entre los seres sociales y otras entidades potenciadoras primarias y secundarias por su necesidad de producir alimentos. En este momento histórico inicial de lo Moche se tiene la existencia de una agricultura de regadío intensivo (Billman, 20 I0: 18I; Gamboa y Nesbitt, 2012: I 18) y, por ello, las comunidades tempranas Moche están siempre relacionadas a los fondos de valle y laderas de cerros vecinos. Este será el punto de partida, pues, produce los alimentos y los espacios físicos necesarios para la reproducción de la vida social (Pozorski, 1979: 175; Billman, 1996; Canziani, 2009). Los momentos de tensión con las entidades potenciadoras primarias se dan cuando las condiciones ecológicas no permitan reproducir las plantas y consumir o reproducir animales. Estas relaciones dialécticas de tensión se superan cuando los seres sociales se organizan de mejor manera para la producción o cuando las condiciones climatológicas mejoran de forma contingente.

Por otra parte, la producción de artefactos también se genera mediante relaciones dialécticas de convivencia entre los seres sociales y las materias primas (entidades potenciadoras primarias) $y$, en principio, tendrá un grado mínimo de tensión en este momento histórico. Durante el trascurso de esta relación dialéctica de convivencia y tensión se establece la producción de artefactos en las diferentes comunidades de los valles de Moche y Chicama como la arquitectura, textilería, alfarería, metalurgia, etc. (ver por ejemplo, Van Gijseghem, 200 I; Millaire, 2008; Fraresso, 2008; Bernier, 2008; Rengifo y Rojas, 2008; Uceda, 20I0b). Esta producción que comienza como una relación dialéctica de convivencia entre seres sociales y entidades potenciadoras primarias y la producción de artefactos que, en principio, es de libre intercambio se convierten en la condición base para su apropiación por otros grupos sociales, especialmente la elite.

Como vimos anteriormente, la necesidad de acumulación de otras entidades potenciadoras primarias y secundarias y el control de la producción de los seres sociales por parte de las elites será la consecuencia de la relación dialéctica tensa entre seres humanos provocada por el alejamiento espacial y laboral de la producción material de un grupo de ellos. Esto irá acompañado de la ocupación y apropiación de sitios con características especiales (huacas) por parte de estos seres sociales, posiblemente, especialistas religiosos a tiempo completo. Es importante señalar que dichas huacas además de estar vinculadas directamente con cerros con características especiales también estaban vinculados a los principales ríos o canales del valle. La concentración de seres humanos y su nueva relación con los artefactos y ecofactos también concentrados, generará lo que conocemos como ciudades. En estos espacios transformados por los seres sociales necesariamente, por relaciones dialécticas de convivencia y el surgimiento de relaciones de tensión, se tendrá que re-organizar la 
vida social en estos nuevos y dinámicos contextos de co-existencia (Uceda, 20 I0a;Attarian 2009: 82).

\section{2.- Relaciones dialécticas entre seres sociales}

Lo primero que hay que señalar aquí es que la reproducción biológica y social en tanto generadora de fuerza de trabajo se da originalmente en una relación dialéctica de convivencia entre hombres y mujeres. Así, una vez resuelto el tema de la reproducción de la vida de los seres sociales a través de la generación de alimentos y artefactos (relación dialéctica entre seres sociales y otras entidades potenciadoras secundarias), fue necesario establecer cómo organizar la vida entre los seres humanos que se encontraban interrelacionados, especialmente en los espacios donde se generaron concentraciones de seres sociales. En algunos casos, se decide socialmente por la convivencia en forma simétrica (comunitaria) pero en el caso de los Moche, finalmente, se generó una relación asimétrica que, como vimos, fue causada principalmente por la apropiación de entidades potenciadoras primarias y secundarias y artefactos por parte de un grupo de seres sociales: los especialistas religiosos a tiempo completo. Tal relación dialéctica tensa se saldó con la composición de una sociedad en la cual la relación entre seres sociales generó que algunos de ellos se apropien principalmente de otras entidades primarias y artefactos e, indirectamente, de los seres sociales mediante el consumo de su trabajo. Esto fue sancionado mediante la religión y la violencia física estableciendo, de esta manera, la presencia fáctica del Estado Moche. Esta situación de asimetría social se hace más evidente hacia el final de la sociedad Moche con la aparición de los denominados "Señores Moche", en la zona urbana de Huaca del Sol y la Luna, los cuales controlarían distintos especialistas dentro de sus propias residencias (Uceda, 20I0b).

Es importante señalar que, durante la existencia del Estado Moche, el hombre detentaba el poder real sobre otros seres sociales y otras entidades. Aunque en algunos momentos tardíos del Estado Moche y en ciertos centros políticoreligiosos algunas mujeres parecen detentar el principal poder religioso-político como la "Señora de Cao" (Mujica, 2007: 219; Franco, 2008), estas solo lo hacen en espacios y lugares exclusivos y siempre reproduciendo las formas de poder político del hombre (Figura 7). Así, en el Estado Moche existía una clara relación dialéctica de tensión entre hombres y mujeres.

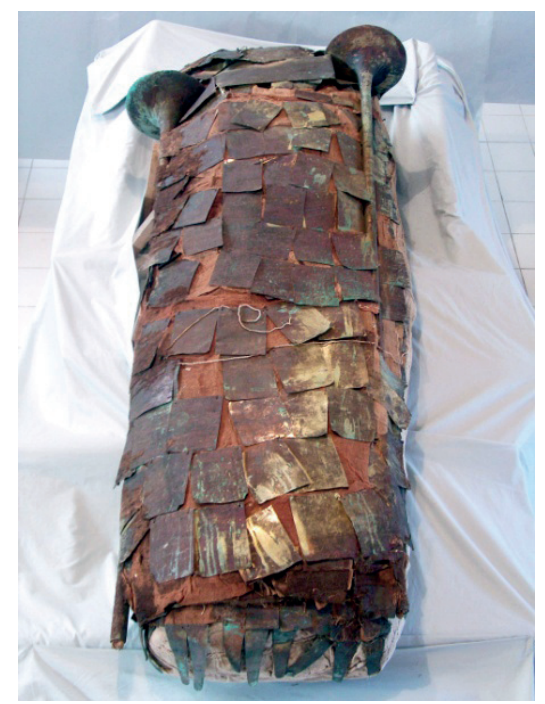

Figura 7: Fardo de la Señora de Cao. Foto de la Fundación Wiesse

Figure 7: Lady of Cao's mummy bundle. Photograph by FundaciónWiesse

Las relaciones dialécticas de tensión entre seres sociales también se pueden ver materializadas en las mismas ciudades como la de Huaca del Sol y la Luna donde, incluso, se materializa dicha relación dialéctica o "dualidad" en los principales edificios, un patrón que también se puede reconocer en otros asentamientos Moche (Quilter, 2002: 175; Franco et al., 2010: 120). Asimismo, aparte de los edificios monumentales, como la Huaca del Sol y la Luna, a medida que se van concentrando los seres sociales y los artefactos, se genera un entramado urbano que materializa las diferencias sociales 0 relaciones dialécticas de tensión y contradicción (Chapdeleine 200I; Toyne et al., 20l4). Las tensiones entre diferentes grupos sociales se materializan desde la misma arquitectura (Van Gijseghem, 200I) hasta los artefactos depositados dentro de los espacios construidos. Adicionalmente, acompañando a la vida de los Moche también en su muerte se puede reconocer dichas relaciones dialécticas de tensión y contradicción en las que se puede ver la existencia de acumulación de artefactos en las tumbas de los líderes políticos enterrados en los principales sectores de los edificios Moche (Strong y Evans, 1952; Mujica, 2007: 177; Franco, 2008). Estos contextos funerarios contrastan fuertemente con los de otros seres sociales que solo pudieron 
procurarse enterramientos humildes (Donnan y Mackey, 1978; Gamboa y Nesbitt, 2012: 130). Asimismo, en diferentes edificios monumentales Moche se han registrado sacrificios humanos en los que seres sociales previa y posteriormente a su muerte, se convirtieron enartefactos (Verano, 200I; Hill, 2003; Millaire, 2004; Sutter y Cortez, 2005; Toyne et al., 20|4).

De este modo, la tensa relación dialéctica entre seres sociales condujo a la institucionalidad de ciertas prácticas económicas, políticas e ideológicas en la sociedad Moche generando finalmente un Estado y ordenando, desde arriba, una serie de jerarquías políticas que garantizaron el establecimiento de una sociedad vertical (Chapdeleine, 2010a). Obviamente, esta organización se halla en una tensión mayor y supone que los comuneros $y$ artesanos quieran liberarse y las elites persistan en ese control y dominio a través de la generación de una serie de estrategias con medios fácticos e ideológicos(Swenson, 2003: 268; Bawden, 2004: I 19; Sutter y Cortez, 2005) para conservar su lugar dentro de la pirámide social. Adicionalmente, la relación dialéctica de tensión entre los seres humanos también se superará creando una ideología oficial, la cual a través de los ritos y fiestas, resulta un potente catalizador y liberador de tensiones entre los diferentes seres sociales con diferentes ubicaciones dentro de la pirámide social Moche. Sin embargo, esta ideología también reproducía un discurso en el cual se sancionaba el lugar que ocupaba cada segmento social, naturalizando $y / o$ encubriendo las diferencias en la vida real. Dentro de ese mismo discurso ideológico, ciertas entidades potenciadoras primarias como los cerros también fueron utilizados para generar una visión del mundo (Bourget, 1994) que sirvió para ordenar a la sociedad desde la perspectiva de la elite e invisibilizar las tensiones sociales existentes (Figura 8 ).

Asimismo, en su desarrollo histórico material e ideológico (sobre todo de la apropiación de artefactos), las elites moche también generaron sus propias facciones (relaciones dialécticas de tensión entre grupos diferenciados de seres sociales dominantes) lo cual llevó a una tensión adentro del grupo social dominante. Por otra parte, en el transcurso de su historia, el ritual y la ideología religiosa tuvieron que ser recreados para seguir

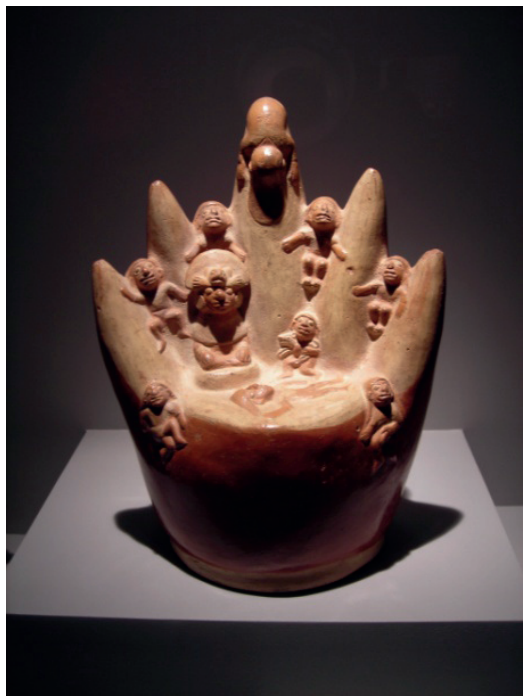

Figura 8: Vasija de Huancaco, valle de Virú. Museo Larco.

Figure 8: Huancaco vessel, Virú valley. Larco Museum

controlando a los seres sociales dominados. El paisaje social se completaba con los grupos especializados que existían en los valles de la costa norte donde pescadores, agricultores, artesanos y otros, establecían sus propias agendas con relación a sus intereses y prácticas colectivas, aunque sin tener la capacidad económica ni política de controlar a otros grupos, control que solo podía detentar el grupo social de la elite a través de la ideología y de la fuerza.

Si aceptamos la propuesta de Uceda (20I0a) de que alrededor del 600 d.C. se abandonó el modelo de Estado teocrático y se pasó a una "secularización del poder", lo que habría generado el control del acceso a los artefactos a una facción de los seres sociales dominantes ("artesanos empoderados"). Siguiendo este planteamiento, la facción religiosa no habría podido controlar plenamente a otros grupos de seres sociales como la elite urbana y esta asumió el control del principal asentamiento arrastrando con ello a la fragmentación del Estado Moche. Sin embargo, otras propuestas (por ejemplo, Chapdeleine, 20I0a) manifiestan que el centro político-religioso de las Huacas del Sol y la Luna continuó ejerciendo control económico y político sobre sus territorios hasta el siglo VII. Independientemente de que se haya dado uno u otro escenario, en ambos casos las relaciones dialécticas de tensión y contradicción previas estaban presentes y posibilitaron el cambio. 
3.- Relaciones dialécticas entre el Estado Moche y otras formaciones sociales

Como todas las anteriores, estas relaciones dialécticas deben verse de forma histórica pues desde el valle de Moche este Estado comenzó a expandirse desde su núcleo original hasta límites que se establecen por el norte hasta el valle de Chicama y por el sur hasta el valle de Huarmey, expansiones que se dieron de maneras e intensidades diferentes (Shimada, 20l0). Así, en principio, la existencia de un asentamiento principal como Huacas del Sol y de la Luna supone la concentración y acumulación de seres sociales y artefactos todos ellos inmersos en relaciones dialécticas de diferentes niveles que hemos visto anteriormente. En sí misma, esta ciudad es un artefacto que representa a la institución económica y política, en este caso el Estado Moche y la capital y centro de dicha sociedad jerarquizada. La ciudad misma en su existencia y dinámica se opone y se enfrenta en la región a otros conjuntos de estructuras habitacionales, aldeas, poblados y ciudades $y$, finalmente, a los comuneros en los campos de cultivo y a otros especialistas como los pescadores. Por tanto, su existencia posibilitará diferentes relaciones dialécticas dentro y fuera del paisaje sociopolítico y socioeconómico de la región. Así,el Estado Moche genera una relación dialéctica tensa hacia fuera de sus fronteras en tanto estructura política frente a otros grupos (formaciones sociales) dentro del paisaje político y económico de la zona, un paisaje necesariamente de desarrollos desiguales dadas las diferentes trayectorias históricas de las otras comunidades de seres sociales y/o entidades sociopolíticas.

En su proceso de expansión, en cada momento histórico, el Estado Moche se enfrentó a algunas sociedades con las que entraron en tensión (Castillo y Uceda, 2008: 708), y en algunos casos absorbiéndolas y/o consumiendo la fuerza social de otras comunidades. Si aceptamos que los "Moche del Norte" conformaron una serie de entidades políticas económica y políticamente independientes (Castillo y Quilter, 2010), debió existir algún tipo de relación con el Estado Moche ("Moche del Sur") que los mantuvo en tensión y cuya materialización se puede observar en las diferentes formas de expresar sus artefactos. Pero también existiría una relación dialéctica de convivencia Moches del Sur $\leftrightarrow$ Moches del Norte, especialmente entre sus elites, lo que explicaría muy bien las similitudes que se encuentran a nivel material e ideológico.

Con respecto a su expansión hacia el sur, el Estado Moche se enfrentó a otras comunidades o formaciones sociales en una relación que siempre permaneció en diferentes niveles de tensión. Vale decir, los grupos sociales controlados, aliados - conquistados, especialmente las elites y sus respectivos comuneros de esos valles, generaron diversos escenarios y reacciones con respecto al Estado Moche (Schaedel, I 95 I; Proulx, I 982; Pimentel y Paredes, 2003; Pozorski y Pozorski, 2006; Bourget 2010; Millaire, 20l0b; Shimada, 2010; Chapdeleine, 20I0b, 20I I; Makowski et al., 20II: 253; Gierzet al. 2013: 45-66).

Otra formación social que también vale la pena tomar en cuenta aquí es la Recuay, la cual fue una contraparte de los Moche y ocupaban un espacio ecológico que les era extraño. Recuay ha sido definida recientemente como una "serie de entidades políticas de jefaturas independientes que estaban en emergencia dentro de un contexto de comunidades dispersas relativamente igualitarias" (Lau, $20 \mathrm{II}$ : I4). Al parecer, entre estas “jefaturas”no existió una integración política aunque si compartieron un estilo cerámico y litoescultórico característico (artefactos) y una forma de asentamiento en los valles interandinos del actual Departamento de Ancash. De hecho, el asentamiento humano en esta región serrana supuso una relación dialéctica con respecto a la producción e intercambio que tuvo varios episodios de convivencia, colaboración y hasta de asimilación de ciertos elementos religiosos (Bruhns, 1976; Proulx, 1982: 89; Mujica, 2007: 126, 146; Shimada, 2010). Sin embargo, también se dieron episodios tensos en que el Estado Moche tuvo que establecer el control de su territorio y recursos por medio de la fuerza (Lau, 2004: I62, 20I4: 322) (Figura 9).

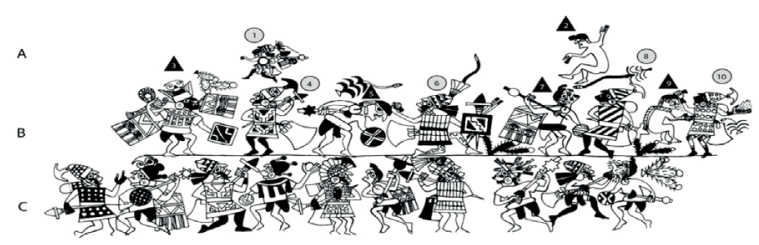

Figura 9: Combate entre guerreros moches y recuays. Tomado de Lau 2004

Figure 9: Battle between moche and recuay warriors. After Lau 2004 
Como vimos anteriormente, las relaciones dialécticas de tensión entre seres sociales dentro del Estado Moche, produjeron la generación y/o reforzamiento de una ideología político-religiosa para justificar su existencia como estado objetiva y subjetivamente (Quilter, 1990) lo cual también se proyectaba hacia fuera de las fronteras del Estado Moche. Por otra parte, hacia el siglo VII el Imperio Wari comenzó a expandirse desde Ayacucho e impactó en diversos niveles en la región andina. Esto creó una relación dialéctica tensa y de contradicción entre estados en un momento en que el Estado Moche había perdido la fuerza que poseía previamente.

En un momento alrededor del siglo IX de nuestra era, las mismas relaciones dialécticas de tensión y contradicción (seres sociales dominados $\leftrightarrow$ seres sociales dominantes) y entre facciones dentro del grupo dominante (seres sociales dominantes $\leftrightarrow$ seres sociales dominantes) $y$, que fueron catalizadas por el establecimiento del Estado Moche, llegaron a su fin. Esto supuso la desaparición de la integración política y económica de la región e, incluso, de los mismos asentamientos como el de la Huaca del Sol y de La Luna que comenzaron a ser abandonados parcialmente y sus principales edificios comenzaron a ser utilizados para funciones diferentes a las originales. Otros asentamientos humanos vinculados con Moche también comenzaron a surgir $y$ ha empoderarse en el paisaje político generando una relación dialéctica entre ciudades que previamente había estado controlada u opacada por un único poder político-religioso centralizado en la margen izquierda del rio Moche (Lockard, 2005, 2009; Gamboa y Nesbitt, 20 I2: 135).

De este modo, uno de los principales factores que condujo a la desaparición del Estado Moche fue la misma tensión dialéctica y contradicciones graves entre seres sociales que generaron una erosión en sus propias relaciones. Dicha situación trató de ser superada por la elite a través de la producción y uso de medios coercitivos e ideológicos sin mucho éxito. Dicha erosión del tejido social creado por la elite Moche también fue acelerada por la relación de tensión existente entre los seres sociales y las entidades potenciadoras primarias,especialmente, impulsada por losdesastres naturales (Shimadaet al. 1991; Van Buren, 200I).

\section{DISCUSIÓN}

Las perspectivas arqueológicas sobre los Moche han cambiado a lo largo de los años (Castillo y Quilter, 20I0; Tinoco, 20I0; Castillo, 20I3). Especialmente, la perspectiva neoevolucionista es la que ha primado en dichas explicaciones implícita y explícitamente (Quilter y Koons, 20I2). Dado que la historia del proceso de formación, desarrollo y desintegración de la sociedad Moche es vista en retrospectiva nos asalta la duda de si nuestra perspectiva dialéctica también resulta teleológica como las anteriores. Sin embargo, superada dicha impresión y reconociendo que la historia se dio de una forma y no de otra, queda claro que una perspectiva dialéctica de los Moche pone el motor del cambio en los mismos actores objetivos de tales cambios: las entidades aquí señaladas. Más importante aún, al reconocer que los diferentes protagonistas tienen potencias que promueven, mantienen $\circ$ detienen el cambio histórico, es posible reconocer materialmente en qué momento histórico cada actor desplegó dicha potencia y superó la resistencia de la entidad a la cual se enfrentó principalmente.

Asimismo, fuera de la sociedad Moche resulta importante retomar el concepto de desarrollo desigual que aparece entre líneas en cualquier estudio regional de las sociedades prehispánicas andinas. $\mathrm{Si}$ bien, esto no es un gran descubrimiento lo que si nos parece relevante es entender que las historias locales al ser enfrentadas entre sí detonan cambios que sin la precedente situación de formación propia no se darían. Así retornamos el motor del cambio histórico a los mismos protagonistas de la historia y no a fuerzas externas a los mismos actores. Finalmente, creemos que esta heurística supone la apertura para un espacio de discusión en el que los nuevos descubrimientos por venir de la sociedad Moche se verán a luz de una perspectiva más amplia en la cual todos los actores, "grandes" y "pequeños", "activos" y "pasivos", "humanos" y "naturales", sean sumados a una perspectiva mucho más dinámica y cambiante de la explicación de la sociedad Moche. Obviamente, este caso es uno de los tantos en la prehistoria peruana y podrá ser tomada en cuenta para otros fenómenos sociales por reflexionar o investigar en el futuro. 


\section{COMENTARIOS FINALES}

La arqueología es la ciencia que estudia en el presente los fenómenos sociales pasados a partir de los restos materiales que puede reunir.Aunque en apariencia este registro arqueológico es inerte, todo un proceso dinámico pasado se ha dado lugar para que nosotros podamos reconocerlo como tal en el momento de nuestro encuentro con este. Es más, en su propio momento existió toda una dinámica en la producción de los artefactos que acompañaron a los seres sociales como parte de la generación de su propio mundo físico y metafísico. Incluso, en algunas ocasiones, somos capaces de encontrar a los restos de los mismos seres sociales que estaban involucrados y hasta produjeron dichos artefactos. Lo que los arqueólogos llamamos “contexto arqueológico", es en sí mismo, la reunión de artefactos y seres sociales, los cuales se nos presentan como estáticos. Sin embargo, como lo es ahora, también en el pasado existieron relaciones dialécticas que produjeron las situaciones históricas que esperamos explicar. Reconocer las relaciones dialécticas es un paso importante para comprender de forma realista cómo se genera la producción de artefactos y seres sociales tomando en cuenta la dimensión de convivencia y tensión que existe en el mundo. Creemos que desarrollar este proyecto teórico-práctico resulta algo necesario por desplegar en la arqueología, pues, definitivamente, además de la teoría que se pueda esbozar, es necesario generar heurísticas y metodologías apropiadas para reconocer cómo se dieron las innumerables relaciones dialécticas presentes en el mundo cotidiano de las sociedades que estudiamos. Al desarrollar esto, podremos evitar las perspectivas teleológicas que concatenan a los eventos históricos en una secuencia lineal que los conduce casi de manera predestinada hacia un lugar que casi siempre resuena con un presente acrítico.

De este modo, el caso de las relaciones dialécticas que se han presentado como forma de explicación de lo Moche $y$, especialmente de la conformación, reproducción, mantenimiento y desaparición del Estado Moche es un claro ejemplo que, gracias a la abundante literatura producida en los últimos años, podemos acercarnos a las plétora de relaciones dialécticas entre los seres sociales y los artefactos desarrolladas en la Costa Norte del Perú durante el primer milenio de nuestra era. Creemos que esta visión dialéctica de las relaciones se corresponde de formas más realista con la generación del mundo social de los Moche. Al fin y al cabo, dicha sociedad fue construida históricamente por sus agentes sociales, tomando decisiones con diferentes fortunas $y$ en las que sus artefactos fueron la compañía que construyó esa personalidad tan especial dentro de la profunda y rica trayectoria histórica de los pueblos andinos que resta por conocer más profundamente.

Agradecimientos: quiero agradecer a Andrés Troncoso por alentarme a publicar este artículo en esta revista. También a los dos evaluadores externos por sus acertados comentarios a este texto. A Thomas Patterson, Edward Swenson y Vicente Lull por revisar las primeras versiones de este manuscrito y hacer importantes comentarios. A mis compañeros del Programa Arqueológico Chincha (PACH): Alexis Rodríguez Yabar, Abel Fernández y Paolo Zorogastúa que escucharon y discutieron una primera aproximación de esta propuesta en el laboratorio de El Carmen. También a Alex González Panta y Carlos Zapata Benítes por realizar comentarios y aportes a este texto. La redacción final de este artículo se pudo realizar gracias a una beca de investigación otorgada por el Proyecto Prometeo de la Secretaria de Educación Superior, Ciencia, Tecnología e Innovación de la República del Ecuador. Finalmente, agradezco a Kelita Pérez Cubas por darme la compañía y tranquilidad necesaria para continuar en la investigación arqueológica.

\section{NOTAS}

Una situación histórica está compuesta por seres sociales y objetos inmersos en una relación dialéctica en un espacio y tiempo concreto.

2 De acuerdo a la segunda edición de The Concise Oxford Dictionary of Archaeology (Darvill, 2009), la heurística es: "Un conjunto de actividades que están diseñadas para lanzar ideas, nuevas maneras de mirar las cosas, o explicaciones alternativas de los fenómenos observados, como un preludio a la formulación de nuevas propuestas y teorías".

3 El concepto de potencia aquí utilizado está inspirado entre otros en Aristóteles (Metafisica), Newton (Principia) y Marx (Grundrisse), intelectuales que vieron un mundo cambiante y dinámico y en que la potencia de los cuerpos era un elemento importante dentro del movimiento de las cosas en el mundo. Para nosotros la potencia es la energía concentrada y contenida en los cuerpos físico-químicos y que se despliega de diferentes formas e intensidades.

4 Por tanto, estamos en contra del "individualismo metodológico" que pretende reconocer al individuo 
como protagonista del cambio social $y$, en consecuencia abstrayéndolo de su propia comunidad y relaciones sociales.

5 Para una discusión de las diferentes definiciones de "agencia" en arqueología ver Robb, 20I I. Para una crítica del concepto y su uso ver Patterson, 2005b.

6 La producción de cerámica relacionada con el estilo Gallinazo se mantiene durante la existencia del fenómeno Moche (Castillo y Uceda, 2008: 717; Shimada, 2010: 73; Chapdeleine, 2008; 134, Millaire y Morlion, 2009).

7 Este conocimiento religioso es una herencia de sus predecesores, especialmente de lo conocido como Cupisnique (Cordy-Collins, 1992; Nesbitt, 2012).

\section{BIBLIOGRAFÍA}

Abbagnano, N. 1971 [1958]. "Cuatro conceptos de dialéctica”. En: La Evolución de la dialéctica, editado por $\mathrm{N}$. Abbagnano, E. Pacci, C. Viano, E. Garin, P. Chiodi, P. Rossi y N. Bobbio, pp. I I-24. Ediciones Martínez Roca, Barcelona.

Allen, C. 1998. "When utensils revolt. Mind, matter, and modes of being in the pre-Columbian Andes". RES: Anthropology and Aesthetics 33:18-27

Alva, W. 1988. "Discovering the New World's richest unlootedtomb”. National Geographic Magazine 147: 510-548.

Alva, W.y C. Donnan. 1993. Tumbas Reales de Sipán. Fowler Museum of Cultural History, Los Angeles.

Angelo, D. 20I4. "Assembling ritual, the burden of the everyday: an exercise in relational ontology in Quebrada de Humahuaca, Argentina". World Archaeology 46(2): 270-287

Arguedas, J. M. 2007 [1966]. Dioses y Hombres de Huarochirí. Narración Quechua recogida por Francisco de Ávila [i 1598?]. Universidad Antonio Ruiz de Montoya, Lima.

Attarian, C. 2009."Urbanism and social change during the Gallinazo and Moche Periods in the Chicama Valley”. En: Gallinazo: An early cultural tradition on the Peruvian North Coast, editado por J.F. Millaire y M. Morlion, pp. 76-89. Cotsen Institute of Archaeology Press, Los Angeles.

Bate, L. F. 2012. "Una nota sobre dialéctica en la “arqueología social”. En: La arqueología social latinoamericana. De la teoría a la praxis, editado por H. Tantaleán y M. Aguilar, pp. 85-I0I. Universidad de los Andes, Bogotá.

Bawden, G. 1996. The Moche. Blackwell, Cambridge.

---- 2004. "The art of Moche politics". En: And e anarchaeology, editado por H. Silverman, Pp. I I6-I29. Blackwell Publishers, Oxford.

Benjamin, W. 2008 [1939-1940]. Tesis sobre la historia y otros fragmentos. Ithaca, México D.F.

Bennett, W. 1950. The Gallinazo Group:Viru Valley, Peru. Yale University Publications in Anthropology 43. Yale University Press, New Haven.

Bernier, H. 2008. "Especialización artesanal en el sitio Huacas de Moche: contextos de producción y Función Sociopolítica". En: Arqueología mochica: Nuevos enfoques, editado por L. J. Castillo, H.Bernier, G. Lockard y J. Rucabado, pp. 33-52. IFEA/PUCP, Lima.
Billman, B. 1996. The Evolution of Prehistoric Political Organizations in the Moche Valley, Peru. Tesis doctoral. University of California, Santa Barbara.

---- 2002. "Irrigation and the origins of the Southern Moche state on the North Coast of Peru". Latin American Antiquity, |3(4): 37|-400.

---- 2010. "How Moche Rulers Came To Power. Investigating the Emergence of the Moche Political Economy". En: New perspectives on moche political organization, editado por J. Quiltery L. J. Castillo, pp. I8I-200. Dumbarton Oaks Research Library and Collection, Washington D.C.

Blanton, R.; G.Feinman, S.Kowalewski\& P. Peregrine. 1996."A dual-processual theory for the evolution of Mesoamerican civilization”. Current Anthropology 37(I): I - I4.

Bobbio, N. 1971 [1958]. "La dialéctica en Marx". En: La evolución de la dialéctica, editado por N. Abbagnano, E. Pacci, C. Viano, E. Garin, P. Chiodi, P. Rossi y N. Bobbio, pp. 253-275. Ediciones Martínez Roca, Barcelona.

Bourdieu, P. 1977. Outline of aTheory of Practice. Cambridge University Press, Cambridge.

Bourget, S. 1994. "Los sacerdotes a la sombra del cerro blanco y del arco bicéfalo". Revista del Museo de Arqueología, Antropología e Historia 5:8I-I25.

----2010. "Cultural assignations during the Early Intermediate Period". En: New perspectives on moche political organization, editado por J. Quiltery L. J. Castillo, Pp. 20I-222. Dumbarton Oaks Research Library and Collection, Washington D.C.

Bourget, S. y K. Jones (eds.). 2008. The Art and Archaeology of the Moche:An ancient andean. Society of the Peruvian North Coast. University of Texas Press, Austin.

Bruhns, K. 1976."The moon animal in northern peruvian art and culture". NawpaPacha 14:21-39.

Brumfiel, E. 1992. "Distinguished lecture in archeology. Breaking and entering the ecosystem-gender, class, and faction steal the show". American Anthropologist 94(3): 55 I-567.

Burger, R.1994. "La organización dual en el ceremonial andino temprano: un repaso comparativo". En: El mundo ceremonial andino, editado por L. Millones y Y. Onuki, pp. 97-I 16. Horizonte, Lima.

Callinicos, A. 2004. Making History. Agency, Structure, Social and Change in Social Theory. Brill, Leiden.

Canziani, J. 2009. Ciudad y Territorio en los Andes: Contribuciones a la Historia del Urbanismo Prehispánico. Fondo Editorial Pontificia Universidad Católica del Perú. Lima.

Castillo, L. J. 20I3. "II0 Años de arqueología mochica: cambios paradigmáticos y nuevas perspectivas”. En: Historia de la arqueología en el Perú del siglo XX, editado por $\mathrm{H}$. Tantaleán y $\mathrm{C}$. Astuhuamán, Pp. 157-205. IFEA/IAR, Lima.

Castillo, L. J. y C. Donnan. 1994. "Los mochicas del norte y los mochicas del sur. Una perspectiva desde el valle de Jequetepeque". En: Vicús, pp. I43-I8I. Colección Arte y Tesoros del Perú. Banco de Crédito del Perú, Lima.

Castillo, L. J. y J. Quilter. 20I0.“Many moche models. An overview of past and current theories and research on 
moche political organization”. En: New perspectives on moche political organization, editado por J. Quilter y L. J. Castillo, Pp. I-I5. Dumbarton Oaks Library and Collections, Washington D.C.

Castillo, L. J. y S. Uceda. 2008. "The mochicas". En: Handbook of South American archaeology, editado por H. Silverman yW. Isbell, pp. 707-729. Springer, New York.

Chapdelaine, C. 200I. "The growing power of a moche urban class". En: Moche art and archaeology in ancient Peru, editado por J. Pillsbury, pp. 69-87. National Gallery of Art,Washington D. C.

---2008. "Moche art style in the santa valley. Between being "à la mode" and developing a provincial identity". En: The art and archaeology of the Moche. An ancient andean society of the Peruvian North Coast, editado por S. Bourget y K. Jones, pp. I29-I 52. University of Texas Press. Austin.

---- 2010a. "Recent advances in moche archaeology". Journal of Archaeological Research 19 (2): 191-231

---20I0b. "Moche political organization in the Santa Valley. A case of direct rule through gradual control of the local population”. En: New perspective son moche political organization, editado por J. Quilter y L.J. Castillo, pp. 252-279. Dumbarton Oaks Library and Collections, Washington D.C.

---- 20II. "Los moches del Santa, una larga historia". En: Arqueología de la costa de Ancash, editado por M. Gierz e Iván Ghezzi, pp. 185-230. Centro de Estudios Precolombinos/IFEA, Varsovia.

Chapdeleine, C., V. Pimentel y H. Bernier. 200I. "A Glimpse at moche-phase-iii occupation at the huacas of moche site, Northern Peru”. Antiquity 75: 36I-372.

Cordy-Collins, A. 1992. "Archaism or tradition?: The decapitation theme in cupisnique and moche iconography”. Latin American Antiquity 3(3): 206-220.

Crumley, C. 200I. "Communication, holism, and the evolution of sociopolitical complexity". En: From leaders to rulers, editado por J. Haas, pp. 19-33. Kluwer Academic/Plenum Publishers, New York.

Darvill, T. 2009. The Concise Oxford Dictionary of Archaeology. Oxford University Press. Oxford.

Descola, P. 2005. Beyond Nature and Culture. University of Chicago Press, Chicago.

Donnan, C. 1978. Moche Art of Peru: Pre-Columbian Symbolic Communication. Museum of Cultural History. University of California, Los Angeles.

---- 2010. "Moche state religion. A unifying force in moche political organization”. En: New perspective son Moche political organization, editado por J. Quilter y L. J. Castillo, pp. 47-69. Dumbarton Oaks Library and Collections. Washington D.C.

---- 201I. "Moche substyles: Keys to understanding moche political organization". Boletín del Museo Chileno de Arte Precolombino I6(I): I05-II8.

Donnan, C. y C.Mackey. 1978. Ancient Burial Patterns of the Moche Valley, Peru. University of Texas Press, Austin.

Fogel, H. 1993. Settlements in Time: A Study of Social and Political Development during the Gallinazo Occupation of the North Coast of Peru. Tesis doctoral. Department of Anthropology, Yale University, New Haven.
Franco, R. 2008. "La Señora de Cao”. En: Señores de los Reinos de la Luna, editado por K. Makowski, pp. 280-287. Banco de Crédito del Perú, Lima.

Franco, R. y C. Gálvez. 2009. “Gallinazo-Style ceramics in early moche contexts at the El Brujo". En: Gallinazo: An early cultural tradition on the Peruvian North Coast, editado por , J.-F. Millaire y M. Morlion, pp. 9I-I 04. CotsenInstitute of Archaeology, UCLA, Los Angeles.

Franco, R., C. Gálvez y S. Vásquez. 20I0. "Moche power and ideology at the El Brujo Complex and in the Chicama Valley". En: New perspective son Moche political organization, editado por J. Quiltery L. J. Castillo, Pp. II0-I3I. Dumbarton Oaks Research Library and Collection,Washington D.C.

Fraresso, C. 2008. "El "sistema técnico" de la metalurgia de transformación en la cultura mochica: Nuevas perspectivas". En: Arqueología mochica: Nuevos enfoques, editado por L. J. Castillo, H. Bernier, G. Lockard y J. Rucabado, Pp. I53-I 7 I. IFEA/PUCP, Lima.

Gamboa, J. y J. Nesbitt. 20I2."La ocupación moche en la margen norte del valle bajo de moche, Costa Norte del Perú”. Arqueología y Sociedad, 25: I I5-| 42.

Giddens, A. 1984. The Constitution of Society. Outline of the Theory of Structuration. Polity Press, Cambridge.

Gierz, M., P.Przadka y K.Makowski. 20I3. Huarmey. En: el Cruce de Caminos del Perú Milenario. Hipocampo, Lima.

Haber, A. 2009. "Animism, relatedness, life: Post-western perspectives”. Cambridge Archaeological Journal 19(3):4I 8-30.

Hill, E. 2003. "Sacrificing moche bodies". Journal of Material Culture 8 (3): 285-299.

Hocquenghem, A. M. 1987. Iconografia Mochica. Pontificia Universidad Católica del Perú, Lima.

Hodder, I. 1995. Theory and Practice in Archaeology. Routledge, Londres.

---- 2012. Entangled. An Archaeology of the Relationships between Humans and Things. Wiley-Blackwell, Malden.

Isbell, W. 1977. "Cosmological order expressed in prehistoric ceremonial centers". Proceedings of the $42 \mathrm{nd}$ International Congress of Americanists 4: 269-297.

Jones, O. y P.Cloke. 2008. “Non-human agencies: Trees in place and time". En:Material agency.Towards a non-anthropocentric approach, editado por C. Knappett y L. Malafouris, Pp. 79-96. Springer, New York.

Lau, G. 2004. "Object of contention: An examination of recuay-moche combat imagery”. Cambridge Archaeological Journal I4(2): I63-184.

---- 20II. Andean Expressions. Art and Archaeology of the Recuay Culture. University of lowa Press, lowa City.

----20I4. "A materiality of opposition: on ancient conflict and organization in Peru's north highlands". En: Embattled bodies, embattled places: War in pre-columbianAmerica, editado por A. Scherer y J. Verano, pp. 3I5-344. Dumbarton Oaks, Washington D.C.

Latour, B. 199I [2007]. Nunca Fuimos Modernos. Ensayo de Antropología Simétrica. Siglo XXI, Buenos Aires.

Lockard, G. 2005. Political Power and Economy at the Archaeological Site of Galindo, Moche Valley, Peru. Tesis doctoral. 
Department of Anthropology. University of New Mexico, Albuquerque.

---- 2009. "The occupational history of Galindo, Moche Valley, Peru”. Latin American Antiquity 20(2): 279-302.

Lull, V. 2007. Los Objetos Distinguidos. La Arqueología como Excusa. Bellatera, Barcelona.

Makowski, K. 2008. "Poder e identidad étnica en el mundo moche”. En: Señores de los Reinos de la Luna, editado por K. Makowski, pp. 55-75. Banco de Crédito del Perú, Lima.

----2 2009. "Virú-Moche relations: Technological identity, stylistic preferences, and the ethnic identity of ceramic manufacturers and users". En: Gallinazo: An early cultural tradition on the Peruvian North Coast, editado por J. F. Millaire y M. Morlion, pp. 33-60. Cotsen Institute of Archaeology Press. Los Angeles.

Makowski, K.,M. Giersz y P. Pradka. 20II. "La guerra y la paz en el Valle de Culebras: hacia una arqueología de fronteras". En: Arqueología de la Costa de Ancash, editado por M. Gierz e I. Ghezzi, pp. 23 I-270. Centro de Estudios Precolombinos/ IFEA, Varsovia.

Marquardt, W. 1992. "Dialectical archaeology". Archaeological Method and Theory 4: I0I-I 40.

McGuire, R. 1992. A Marxist Archaeology. Academic Press, New York.

---- 1998. "Una aproximación marxista dialèctica a I'arqueologia”. Cota Zerol4: 6I-72.

McGuire, R. y D.Saitta. 1996. "Although they have petty captains, they obey them badly: The dialectics of prehispanic western pueblo social organization". American Antiquity 6 I (2): I 97 216.

Millaire, J. F. 2004."The Manipulation of Human Remains in Moche Society: Delayed Burials, Grave Reopening, and Secondary Offerings of Human Bones on the Peruvian North Coast". Latin American Antiquity, I 5(4): 37I-388.

---- 2008. "Moche textile production on the Peruvian North Coast. A contextual analysis". En: The art and archaeology of the Moche. An ancient andean society of the Peruvian North Coast, editado por S. Bourget y K. Jones, pp. 229-245. University of Texas Press, Austin.

---- 2009a. "Gallinazo and the tradición norcosteña". En: Gallinazo: An early cultural tradition on the Peruvian North Coast, editado por J. F. Millaire y M. Morlion, Pp. I-16. Cotsen Institute of Archaeology Press, Los Angeles.

---- 2009b. "Woven identities in the Virú Valley". En: Gallinazo: An early cultural tradition on the Peruvian North Coast, editado por J. F. Millaire y M. Morlion, pp. I49-165. Cotsen Institute of Archaeology Press. Los Angeles.

---- 2010a. "Primary state formation in the Virú Valley, North Coast of Peru". Proceedings of National Academy of Sciences I07(14): 6186-6191.

---- 20l0b. "Moche political expansionism as viewed from Virú". En: new perspectives on moche political organization, editado por J. Quiltery L. J. Castillo, pp. 223-25I. Dumbarton Oaks Research Library and Collection, Washington, D.C.

Millaire, J. F. y M. Morlion (eds.). 2009. Gallinazo:An early cultural tradition on the Peruvian North Coast. Cotsen Institute of Archaeology Press, Los Angeles.
Miller, D. y C.Tilley. 1984 "Ideology, power, and prehistory: An introduction”. En: Ideology, Power, and prehistory, editado por D. Miller y C. Tilley, Pp. I-I5. Cambridge University Press. Cambridge.

Moore, J. 1995. "The archaeology of dual organization in Andean South America: A theoretical review and case study". Latin American Antiquity 6(2): I65-I8I.

Mujica, E. (ed.). 2007. El Brujo. Huaca Cao, centro ceremonial moche en el valle de Chicama. FundaciónWiesse, Lima.

Nesbitt, J. 2012 Excavations at Caballo Muerto: An Investigation into the Origins of the Cupisnique Culture. Tesis doctoral. Yale University.

Olsen, B. 2010. In Defense of Things. Archaeology and the Ontology of Objects. Alta Mira Press. Lanham.

Patterson, T. 1990. "Some theoretical tensions within and between the processual and postprocessual archaeologies". Journal of Anthropological Archaeology 9: 189-200.

---- 2003. Marx's Ghost. Conversations with Archaeologists. Berg, Oxford.

---- 2004. "Class conflict, state formation and archaism. Some instances from ancient Peru". Journal of Social Archaeology 4(3): 288-306.

---- 2005a. "Craft specialization, the reorganization of production relations and state formation". Journal of Social Archaeology 5(3): 307-337.

---- 2005b. "The turn to agency: Neoliberalism, individuality, and subjectivity in late-twentieth-century anglophone archaeology”. Rethinking Marxism I7(3): 373-384.

Pauketat, T. 2007. Chiefdoms and Other Archaeological Delusions. Altamira Press, Landham.

Pillsbury, J. (ed.). 200I. Moche Art and Archaeology in Ancient Peru. National Gallery of Art, Washington D.C.

Pimentel, V. y M. Paredes. 2003.“Evidencias Moche V en tambos y caminos entre los valles de Santa y Chao, Peru”. En: Moche: hacia el final del milenio: actas del segundo coloquio sobre la Cultura Moche, editado por Uceda, Santiago y Elías Mujica, Tomo I, Pp. 269-303. Pontificia Universidad Católica del Perú, Lima.

Pozorski, S. 1979."Prehistoric diet and subsistence of the Moche Valley, Peru”. World Archaeology I I (2): I63-I84.

Pozorski, T. y S. Pozorski. 2006. "Discoveries of Moche ceramics in the Casma Valley, Peru”. Nawpa Pacha 28:129140.

Proulx, D. 1982. "Territoriality in the early intermediate period:The case of Moche and Recuay". NawpaPacha 20: 83-96

Quilter, J. 1990. “The Moche revolt of the objects”. Latin American Antiquity I ( I): 42-65.

--2002. "Moche politics, religion, and warfare". Journal of World Prehistory 16: I45-195.

----20 20.“Moche: Archaeology, ethnicity, identity”. Bulletin de l'Institut Français d'Études Andines 39(2): 225-24I.

Quilter, J. y L. J. Castillo. 20I0. "Many Moche models: an overview of past and current theories and research on Moche political organization". En: New Perspectives on Moche Political Organization, editado por J. Quilter y L. J. Castillo. Dumbarton Oaks Research Library and Collection. Washington. 
Quilter, J. y M,Koons. 20I2." "The fall of the Moche: A critique of claims for South America's first state". Latin American Antiquity 23(2): I27-143.

Rengifo, C. y C. Rojas. 2008. "Talleres especializados en el conjunto arqueológico Huacas de Moche: el carácter de los especialistas y su producción”. En: Arqueología mochica: nuevos enfoques, editado por L. J. Castillo, H. Bernier, G. Lockard y J. Rucabado, pp. 325-339. IFEA/PUCP, Lima. 493-520.

Robb, J. 20II. "Beyond agency". World Archaeology 42(4):

Saitta, D. y R. McGuire. 1998. "Dialectics, heterarchy, and western pueblo social organization”. American Antiquity 63(2): 334-336. Aires.

Sandor, P. 1986. Historia de la Dialéctica. Leviatán, Buenos

Schaedel, R. 1951. "Mochica murals at Pañamarca". Archaeology 4(3): | 45-I54.

Shady, R. 2006. "La civilización Caral: sistema social y manejo del territorio y sus recursos. Su trascendencia en el proceso cultural andino”. Boletín de Arqueología PUCP 10: 59-89. 292-295.

Shanks, M. 2007. “Arqueología simétrica”. Complutum I8:

Shanks, M. y C. Tilley. 1987. Social Theory and Archaeology. Polity Press, Cambridge.

Shimada, I. 2010. "Moche sociopolitical organization. Rethinking the data, approaches, and models". En: New perspectives on moche political organization, editado por J. Quilter y L. J. Castillo, pp. 70-82. Dumbarton Oaks Library and Collections, Washington D.C.

Shimada, I., C. Barker Schaaf, L. Thompson y E. Mosley-Thompson. 1991. "Cultural impacts of severe droughts in the prehistoric Andes: Application of a 1,500-year ice core precipitation record". World Archaeology 22(3): 247-270.

Sillar, B. 2009. "The social agency of things? Animism and materiality in the Andes". Cambridge Archaeological Journal 19(3): 367-377.

Strong, W.D. y C. Evans. 1952. Cultural Stratigraphy in the Viru Valley, Northern Peru:The Formative and Florescent Epochs. Columbia University Press, New York.

Sutter, R. 2009. "Biological origins and relations among Cerro Oreja and other prehistoric northern Andean mortuary populations using epigenetic dental traits". En: Gallinazo: An early cultural tradition on the Peruvian North Coast, editado por J. F. Millaire y M. Morlion, pp. 125-147. Cotsen Institute of Archaeology Press. Los Angeles.

Sutter, R. y R. Cortez. 2005. "The nature of Mochehuman sacrifice. A bio-archaeological perspective”. Current Anthropology 46(4): 521-549.

Swenson, E. 2003. "Cities of violence. Sacrifice, power and urbanization in the Andes". Journal of Social Archaeology 3(2): 256-296.

--2014."The materialities of place making in the ancient Andes: A critical appraisal of the ontological turn in archaeological interpretation". Journal of Archaeological Method and Theory 21 doi: 10.1007/s 10816-014-9202-2

Swenson, E. y J. Warner. 2012. "Crucibles of power: Forging copper and forging subjects at the Moche Ceremonial
Center of Huaca Colorada, Peru". Journal of Anthropological Archaeology 31: 314-333.

Tilley, C. 1982. "Social formation, social structures and social change". En: Symbolic and structural archaeology, editado por I.Hodder, pp. 26-38. Cambridge University Press. Cambridge.

---- 1994. A Phenomenology of Landscape. Places, Paths and Monuments. Berg, Oxford.

---- 2004. The Materiality of Stone. Explorations in Landscape Phenomenology: I. Berg,Oxford.

Tinoco, I. 2010. "Hacia un nuevo paradigma de Moche: interpretaciones acerca de la relación entre las tradiciones culturales Moche y Gallinazo". Anales del Museo de América I8: 99-123.

Topic, T. 1977. Excavations at Moche. Tesis doctoral. Harvard University, Cambridge.

Toyne, M., C. White, J.Verano, S.Uceda, J. F.Millaire y F. Longstaffe. 20I4. "Residential histories of elites and sacrificial victims at Huacas de Moche, Peru, as reconstructed from oxygen isotopes". Journal of Archaeological Science 42: I5-28.

Uceda, S. 2010a."Theocracy and secularism. Relationships between the temple and urban nucleus and political change at the Huacas de Moche". En: New perspectives on Moche political organization, editado por J. Quilter y L. J. Castillo, pp. I32-I58. Dumbarton Oaks Research Library and Collection, Washington D.C.

---- 20l0b. "Los contextos urbanos de producción artesanal en el complejo arqueológico de las Huacas del Sol y de la Luna". Bulletin de I'Institut Français d' Études Andines 39(2): 243-297.

Uceda, S., H.Gayoso y N. Gamarra. 2009. "The Gallinazo at Huacas de Moche: Style or culture?”. En: Gallinazo:An early cultural tradition on the Peruvian North Coast, editado por J.-F. Millaire y M. Morlion, pp. I05- I 23. Cotsen Institute of Archaeology Press, Los Angeles.

Van Buren, M. 200I."The archaeology of El Niño events and other 'natural' disasters". Journal of Archaeological Method and Theory 8(2): I29-I49.

Van Gijseghem, H. 200I. "Household and family at Moche, Peru: An analysis of building and residence patterns in a prehispanic urban center". Latin American Antiquity I2(3): 257-273.

Verano, J. 200I. "War and death in the Moche world: Osteological evidence and visual discourse". En: Moche art and archaeology in ancient Peru, editado por J. Pillsbury, Pp. III-I 25. National Gallery of Art. Washington D.C.

Viveiros de Castro, E. 2010. Metafisicas Caníbales. Líneas de Antropología Postestructural. Katz. Buenos Aires.

Žižek, S. 2006. The Parallax View. Massachusetts Institute of Technology, Cambridge. 